\title{
Traumatic Carotid-Cavernous Fistula Associated With Persistent Primitive Trigeminal Artery Treated by Transarterial Coil Embolization
}

\author{
-Case Report-
}

\author{
Nozomu KOBAYASHI, ${ }^{1}$ Shigeru MIYACHI, ${ }^{2}$ \\ Sachie OI, ${ }^{3}$ and Naohito YAMAMOTO ${ }^{1}$
}

${ }^{1}$ Department of Neurosurgery, Kainan Hospital,

Aichi Prefectural Welfare Federation of Agricultural Cooperatives, Yatomi, Aichi; ${ }^{2}$ Department of Neurosurgery, Nagoya University Graduate School of Medicine, Nagoya, Aichi;

${ }^{3}$ Department of Neurosurgery, Chubu-Rosai Hospital, Nagoya, Aichi

\begin{abstract}
A 30-year-old woman presented with traumatic carotid-cavernous fistula associated with persistent primitive trigeminal artery (PPTA) manifesting as right conjunctival chemosis, exophthalmos, and diplopia. The lesion was treated successfully by trans-arterial coil embolization using the double catheter method with balloon assist. Injury to the PPTA is relatively rare and the PPTA should be sacrificed together with the fistula during the repair.
\end{abstract}

Key words: traumatic carotid-cavernous fistula, persistent primitive trigeminal artery, coil embolization, double catheter, balloon assist

\section{Introduction}

Persistent primitive trigeminal artery (PPTA) is the most common type of fetal carotid-basilar anastomosis persisting into adulthood, and is found in approximately $0.02-0.6 \%$ of the population. ${ }^{9,16)}$ Carotid-cavernous fistulas (CCFs) associated with PPTA are rare, especially secondary to trauma. ${ }^{7)}$ We report a case of traumatic CCF associated with PPTA in a 30-year-old woman who was successfully treated using trans-arterial sinus coil embolization with the double catheter technique.

\section{Case Report}

A 30-year-old woman was involved a motor vehicle accident and suffered a left leg fracture. She also had severe head trauma, but radiological assessment found no brain contusion or skull fracture. She had no neurological signs except for pulsatile tinnitus. Two months later, she suffered right conjunctival chemosis, exophthalmos, and diplopia, which gradually deteriorated. She was referred to our hospital for treatment.

Magnetic resonance imaging showed marked flow voids in the right cavernous sinus (CS) and superior ophthalmic vein (SOV), strongly suggestive of a CCF (Fig. 1A). Cerebral angiography revealed a high flow arteriovenous shunt from the right internal carotid artery (ICA) to the

Received May 11, 2010; Accepted June 23, 2010
CS, draining into the SOV and vein of Galen via the uncal vein. The bilateral inferior petrosal sinuses (IPSs) were occluded (Fig. 1B). Vertebral angiography showed the shunt flow via the injured PPTA (Fig. 1C, D).

The fistula site was expected to be located at just around the origin of the PPTA from the ICA, so transarterial sinus packing with coils from both approaches via the ICA and PPTA was planned. A 7 F balloon catheter (Patrieve; Clinical Supply, Kakamigahara, Gifu) was placed in the right ICA to reduce the shunt flow. A microcatheter was introduced into the CS and advanced towards the origin of SOV. Simultaneously, a 6 F-guiding catheter (Emvoy; Cordis Endovascular, Bridgewater, New Jersey, USA) was placed in the right vertebral artery (VA), and another microcatheter was navigated through the guiding catheter into the posterior portion of the right CS through the PPTA (Fig. 2). Detachable coils were simultaneously inserted into the CS from these two microcatheters to control the bi-directional shunt flow from the ICA and VA at the same time. During the procedure, a 10th coil inserted from the PPTA tended to protrude into the ICA through the orifice of the fistula. Therefore, the microcatheter from the ICA was exchanged for a microballoon catheter (HyperGlide $4.0 \times 15$; ev3, Plymouth, Minnesota, USA), and placed at the orifice to avoid coil herniation (Fig. 3). Complete occlusion of the CCF with the PPTA was finally achieved using 18 coils with preservation of the ICA.

The patient's symptoms of pulsatile tinnitus and exophthalmos resolved immediately after the procedure 


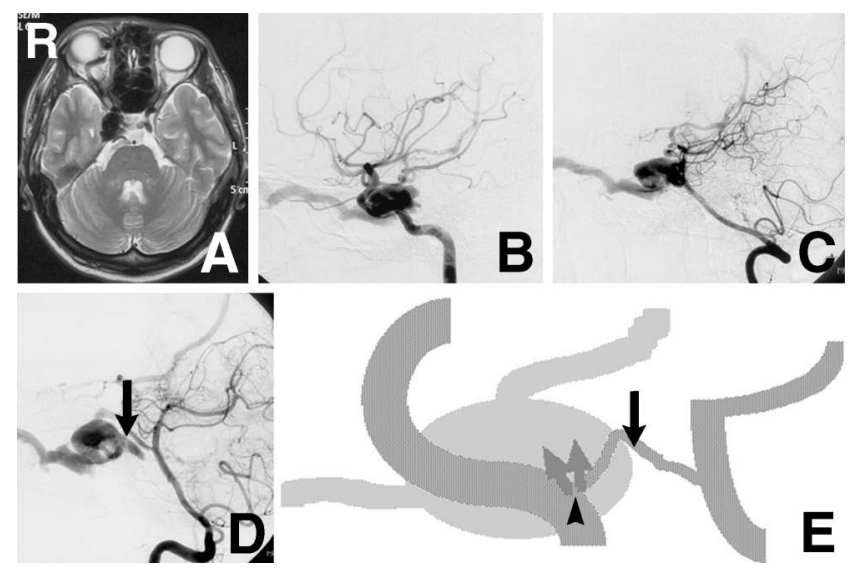

Fig. 1 A: $\mathrm{T}_{2}$-weighted magnetic resonance image showing signal voids in the cavernous sinus and superior ophthalmic vein. B, C: Right internal carotid (B) and left vertebral (C) angiograms showing direct carotid-cavernous fistula with high shunt flow from the right internal carotid artery and basilar artery draining into the superior ophthalmic vein and cerebral veins due to inferior petrosal sinus occlusion. D: Left vertebral angiogram, oblique view, revealing high shunt flow from the persistent primitive trigeminal artery (PPTA) (arrow). E: Schematic diagram of the shunt lesion showing the relationship between the PPTA (arrow) and the shunt point (arrowhead).

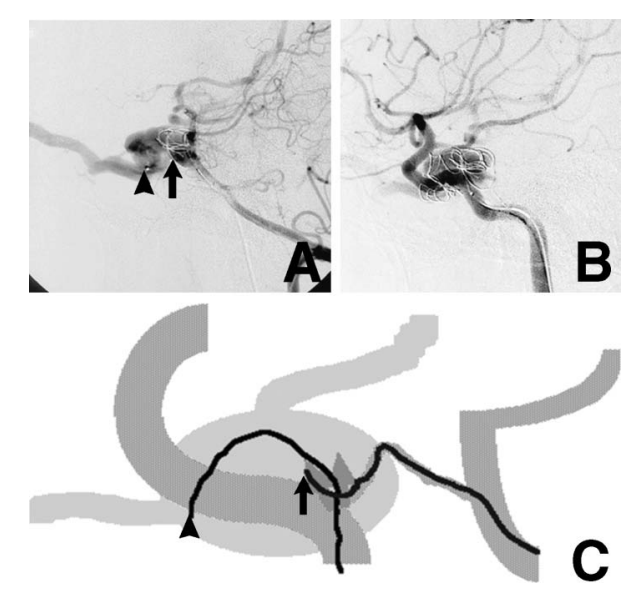

Fig. 2 Trans-arterial embolization using the double catheter technique. A: Left vertebral angiogram showing a microcatheter trans-arterially navigated into the cavernous sinus (CS) from the persistent primitive trigeminal artery (PPTA) (arrow), and another catheter from the internal carotid artery (ICA) already placed (arrowhead). B: Right internal carotid angiogram showing a microcatheter trans-arterially navigated into the CS from the right ICA, and the first two coils being placed. C: Schematic diagram showing the relationship of the two microcatheters from the ICA (arrowhead) and the PPTA (arrow).

with only residual mild right trochlear nerve palsy, which required several months to recover.

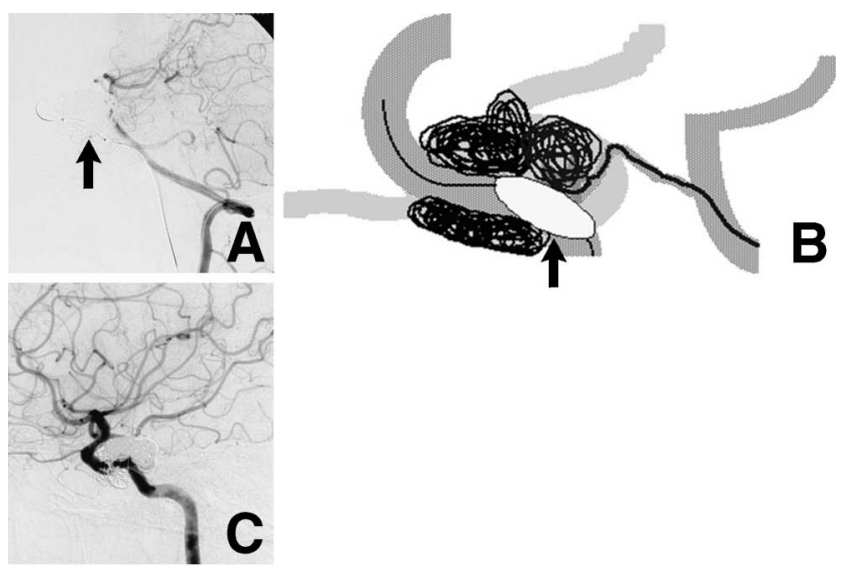

Fig. 3 Trans-arterial embolization using the double catheter technique (continued). A: Left vertebral angiogram showing a microballoon catheter (arrow) placed in the internal carotid artery (ICA) to maintain patency during coil insertion from the primitive trigeminal artery. B: Illustration showing the relationships between the microballoon catheter (arrow), the microcatheter, and the ICA. C: Repeat right carotid angiogram showing the shunt flow is completely obliterated.

\section{Discussion}

Endovascular repair of the injured artery is very effective to treat direct CCFs. ${ }^{11)}$ Fistula occlusion using a detachable balloon appears promising, ${ }^{4,8,10,12,13)}$ but is sometimes technically difficult to achieve in the setting of traumatic fistula with a small orifice. ${ }^{11)}$ In our case, the shunt flow was not very high because the fistula formation was probably not due to direct injury or laceration of ICA, but rather to secondary injury to the PPTA at the intracavernous portion of the ICA. Therefore, we felt that passage of the balloon through the fistula would be impossible, so we decided instead to use coil packing under flow control using a balloon catheter. We placed detachable coils from two directions by the double catheter technique to avoid coil migration by simultaneous control of the bi-directional shunt flows, which achieved definite occlusion of the dangerous drainage route to prevent venous overload. ${ }^{14,17)}$

In our case, angiography revealed bilateral IPS occlusions, which were the cause of the delayed ocular symptoms emerging several months after the trauma. Therefore, we expected that the trans-venous approach would be difficult, and so we selected the trans-arterial approach. The catheterization was quite easy and successful due to the antegrade shunt flow. We also used a microballoon catheter placed in the orifice of ICA to prevent coil herniation. A large number of coils packed in the sinus interferes with the identification of ICA and might cause unnoticed coil protrusion into the ICA. In our case, coil migration into the ICA was prevented before the detachment of the coils because we could see the coil migrating to the distal ICA. Such use of the microballoon catheter should be effective to avoid accidental coil herniation. The observation of a coil in the CS directly protruding into the ICA might suggest that the fistula involved laceration of the 
Table 1 Reported cases of direct carotid-cavernous fistula associated with persistent primitive trigeminal artery

\begin{tabular}{|c|c|c|c|c|c|c|}
\hline $\begin{array}{l}\text { Case } \\
\text { No. }\end{array}$ & Author (Year) & $\underset{\text { (yrs)/Sex }}{\text { Age }}$ & Origin & Treatment & Complication & $\begin{array}{c}\text { VA } \\
\text { hypoplasty }\end{array}$ \\
\hline 1 & Enomoto et al. $(1977)^{6)}$ & $42 / \mathrm{F}$ & spontaneous & ICA ligation & none & - \\
\hline 2 & Kerber and Manke $(1983)^{10)}$ & $26 / \mathrm{M}$ & spontaneous & balloon placement & none & - \\
\hline 3 & $\begin{array}{l}\text { Berger and Hosonuchi } \\
(1984)^{11}\end{array}$ & $51 / \mathrm{F}$ & spontaneous & $\begin{array}{l}\text { failure of balloon procedure/direct } \\
\text { surgery }\end{array}$ & $\begin{array}{l}\text { transient sixth } \\
\text { cranial nerve } \\
\text { palsy }\end{array}$ & - \\
\hline 4 & Flandroy et al. $(1987)^{7)}$ & $35 / ?$ & trauma & $\begin{array}{l}\text { spontaneous regression during } \\
\text { balloon procedure }\end{array}$ & none & - \\
\hline $\begin{array}{l}5 \\
6\end{array}$ & Debrun et al. $(1988)^{5)}$ & $\begin{array}{l}30 / \mathrm{M} \\
49 / \mathrm{F}\end{array}$ & $\begin{array}{l}\text { trauma } \\
\text { spontaneous }\end{array}$ & $\begin{array}{l}\text { balloon placement } \\
\text { balloon placement/ICA occlusion }\end{array}$ & $\begin{array}{l}\text { none } \\
\text { none }\end{array}$ & - \\
\hline 7 & & $67 / F$ & spontaneous & balloon placement/ICA occlusion & none & - \\
\hline 8 & Cheng and Wang (1990) $)^{3)}$ & $42 / \mathrm{F}$ & trauma & direct surgery & none & - \\
\hline 9 & Guglielmi et al. $(1990)^{8)}$ & $20 / \mathrm{M}$ & trauma & - & & - \\
\hline 10 & & $57 / \mathrm{M}$ & spontaneous & balloon placement & none & - \\
\hline 11 & McKenzie et al. (1996) ${ }^{13)}$ & $36 / \mathrm{M}$ & trauma & balloon placement & none & - \\
\hline 12 & Bernstein et al. $(1998)^{2)}$ & $53 / \mathrm{F}$ & spontaneous & $\begin{array}{l}\text { transvenous/transarterial coil } \\
\text { embolization }\end{array}$ & $\begin{array}{l}\text { transient ischemic } \\
\text { attack }\end{array}$ & - \\
\hline 13 & Masaryk et al. (1999) ${ }^{12)}$ & $43 / \mathrm{F}$ & spontaneous & $\begin{array}{l}\text { balloon placement with safety } \\
\text { balloon }\end{array}$ & none & - \\
\hline 14 & Cook et al. $(2000)^{4)}$ & $83 / \mathrm{F}$ & trauma & balloon placement & none & - \\
\hline 15 & Oka et al. $(2000)^{15)}$ & $58 / \mathrm{F}$ & spontaneous & transvenous coil embolization & insufficient closure & - \\
\hline 16 & Tokunaga et al. (2004) $)^{17)}$ & $61 / F$ & spontaneous & $\begin{array}{l}\text { transarterial coil embolization with } \\
\text { double catheter }\end{array}$ & none & - \\
\hline
\end{tabular}

ICA: internal carotid artery, F: female, M: male, VA: vertebral artery.

PPTA origin close to the ICA.

Direct CCF associated with PPTA is not common, with only 16 previously reported cases (Table 1). ${ }^{1-8,10,12,13,15,17)}$ Only 6 cases were traumatic CCFs and the remaining 10 were non-traumatic, spontaneous cases, which may indicate structural fragility allowing easy aneurysm formation and rupture at the origin of a congenital persistent artery like the PPTA. ${ }^{1,17)}$

The patterns of the vertebro-basilar system with PPTA can be classified into two predominant types: Pure persistent PPTA with upper basilar flow dependent upon the PPTA due to hypoplasty of the proximal basilar artery (BA), and hybrid type with the BA flow supplied from both PPTA and VAs. ${ }^{13)}$ It is very important to consider the treatment strategy carefully, especially regarding whether or not the PPTA should be sacrificed. ${ }^{13)}$ Our case was of the hybrid type of BA-PPTA system, as were all previous cases (Table 1), which may suggest that the hybrid type of PPTA is more fragile. Therefore, the PPTA should be sacrificed in cases of the hybrid type to achieve complete obliteration of the shunt and to avoid recurrence.

Direct CCF associated with a PPTA was treated by trans-arterial embolization using the double catheter technique to achieve an excellent result. Traumatic CCF caused by injury of the PPTA is relatively rare, but the fistula site was small and transarterial coil embolization of the fistula was very effective. The double approach from the ICA and the BA via the PPTA is particularly important in cases of the hybrid type of BA-PPTA system to achieve excellent results without a remnant shunt.

\section{References}

1) Berger MS, Hosonuchi Y: Cavernous sinus fistula caused by intracavernous rupture of a persistent primitive trigeminal artery. J Neurosurg 61: 391-395, 1984

2) Bernstein K, Teitelbaum GP, Herman B, Giannotta SL: Coil embolization of a trigeminal-cavernous fistula. AJNR Am J Neuroradiol 19: 1953-1954, 1998

3) Cheng WC, Wang AD: Carotid-cavernous sinus fistula associated with a primitive trigeminal artery. Neurosurgery 27: 802-805, 1990

4) Cook BE Jr, Leavitt JA, Dolan JW, Nichols DA: Carotid cavernous fistula associated with persistent primitive trigeminal artery. J Neuroophthalmol 20: 264-265, 2000

5) Debrun GM, Davis KR, Nauta HJ, Heros RE, Ahn HS: Treatment of carotid cavernous fistulae or cavernous aneurysms associated with a persistent trigeminal artery: report of three cases. AJNR Am J Neuroradiol 9: 749-755, 1988

6) Enomoto T, Sato A, Maki Y: Carotid-cavernous fistula caused by ruptured of a primitive trigeminal artery aneurysm. J Neurosurg 46: 373-376, 1977

7) Flandroy P, Lacour P, Marsault C, Stevenaert A, Collignon J: The intravascular treatment of a cavernous fistula caused by rupture of a traumatic carotid trigeminal aneurysm. Neuroradiology 29: 308-311, 1987

8) Guglielmi G, Vinuela F, Dion J, Duckwiler G, Cantore G, Delfini R: Persistent primitive trigeminal artery-cavernous sinus fistulas: report of two cases. Neurosurgery 27: 805-809, 1990

9) Huber P: Internal carotid artery, in Krayenbuhl H, Yasargil MG (eds): Cerebral Angiography, second completely revised edition. New York, Thieme Medical Publishers, 1982, pp 58-61

10) Kerber CW, Manke W: Trigeminal artery to cavernous sinus fistula treated by balloon occlusion-case report. J Neurosurg 58: 611-613, 1983

11) Kobayashi N, Miyachi S, Negoro M, Suzuki O, Hattori K, Kojima T, Yoshida J: Endovascular treatment strategy for direct carotid-cavernous fistulas resulting from rupture of intracavernous carotid aneurysms. AJNR Am J Neuroradiol 
24: 1789-1796, 2003

12) Masaryk TJ, Perl J II, Wallace RC, Magdinec M, Chyatte D: Detachable balloon embolization: concomitant use of a second safety balloon. AJNR Am J Neuroradiol 20: 1103-1106, 1999

13) McKenzie JD, Dean BL, Flom RA: Trigeminal-cavernous fistula: Saltzman anatomy revisited. AJNR Am J Neuroradiol 17: 280-282, 1996

14) Motoyama $Y$, Ohnishi H, Koshimae N, Kanemoto $Y$, Ida $Y$, Fujimoto K: [A case of high flow CCF with congestive hemorrhage]. No Shinkei Geka 28: 647-651, 2000 (Japanese)

15) Oka Y, Sadamoto K, Tagawa M, Kumon Y, Sakaki S, Fujita M: Transvenous embolization of carotid-cavernous sinus fistula associated with a primitive trigeminal artery-case report. Neurol Med Chir (Tokyo) 40: 61-64, 2000
16) Osborn AG: Internal carotid artery, in Osborn AG (ed): Diagnostic Cerebral Angiography, second edition. Philadelphia, Lippincott Williams \& Wilkins, 1999, p 91

17) Tokunaga K, Sugiu K, Kameda M, Sakai K, Terasaka K, Higashi T, Date I: Persistent primitive trigeminal arterycavernous sinus fistula with intracerebral hemorrhage: endovascular treatment using detachable coils in a transarterial double-catheter technique. J Neurosurg 101: 697-699, 2004

Address reprint requests to: Nozomu Kobayashi, MD, Department of Neurosurgery, Kainan Hospital, 396 Minami-Honden, Maegasu-cho, Yatomi, Aichi 498-8502, Japan.

e-mail: cbk71850@pop06.odn.ne.jp 